\title{
Selective Acetone-Water Delignification of Eucalyptus urograndis: An Al- ternative Towards the Biorefinery Approach
}

\author{
Denilson da Silva Perez ${ }^{* 1,2}$ and Antonio Aprigio S. Curvelo ${ }^{2}$ \\ ${ }^{1}$ Institut Technologique FCBA - Pôle Nouveaux Matériaux - BP 251, 38044 - Grenoble - France \\ ${ }^{2}$ Instituto de Quimica de São Carlos, Universidade de São Paulo. P.O. Box 780, 13.560-970 - São Carlos - SP - Brazil
}

\begin{abstract}
Acetone-water (50:50 v/v) delignification of Eucalyptus urograndis (a hybrid of Eucalyptus urophylla and Eucalyptus grandis) was studied at temperatures ranging from $145^{\circ} \mathrm{C}$ to $195^{\circ} \mathrm{C}$. Lignin and polysaccharide extraction kinetics were determined from pulp yield and residual lignin measurements. Arrhenius-type activation energy of initial, bulk and residual delignification phases were estimated respectively as $102.3,117.7$ and $89.0 \mathrm{~kJ}^{\mathrm{mol}} \mathrm{mol}^{-1}$. For polysaccharide removal, the values were 119.4 and $177.9 \mathrm{~kJ}$ for slower and faster reactions, respectively.

The selectivity of the acetone-water delignification was approached through the interrelationship between delignification and polysaccharide removal. In contrast to kraft pulping, high selectivity is observed in the beginning of the pulping process and then decreases along the process. The first derivative of the lignin extraction curve presents two maxima, one in the beginning of the extraction and the second one between $65 \%$ and $50 \%$ of pulp yield and can speculating be related to the initial and bulk delignification phases. On the other hand, polysaccharides, probably hemicelluloses, are selectively extracted between 85 and $65 \%$ of pulp yield. The process fits perfectly with the biomass biorefinery approach which consists in selectively separate and add-value to different fractions of wood.
\end{abstract}

Keywords: Biorefinery, delignification, organosolv, pulping, acetone-water, Eucalyptus urograndis, kinetics, activation energy, selectivity.

\section{INTRODUCTION}

The interest in developing ecologically adapted, and both economically and technically feasible wood pulping processes, has increased in the last decades. In this context, organosolv pulping was proposed as a promising alternative for chemical pulp production in the past decades. Several papers have reviewed solvent mixtures, pulp characteristics, as well as the advantages and problems of the processes for pulping purposes [1-7]. In order to point out the economical features of the organosolv processes, Curvelo and coworkers have studied the delignification of lignocellulosic raw materials using low cost solvent mixtures [8-11]. An important regain of interest on organosolv pulping has been observed in the recent years as part of the biorefinery concept due to better selectivity of extraction of the different wood components compared to the traditional pulping liquors [12-16].

The purpose of a delignification process is to remove as much lignin as possible while preserving the wood polysaccharides. However, it is well established that it is practically impossible to remove lignin without some carbohydrate degradation. According to Göring, the extraction of

*Address correspondence to this author at the Institut Technologique FCBA - Pôle Nouveaux Matériaux - BP 251, 38044 - Grenoble - France;

Tel: (+33) 476761011 ; Fax: (+33) 4767610 15;

E-mail: denilson.dasilvaperez@fcba.fr polysaccharides leads to the formation of pores in the cell wall matrix allowing the lignin fragments from the secondary wall and middle lamella to be extracted [17]. Thus, the kinetics of delignification and polysaccharide removal, and selectivity are important parameters for the determination of the best operation and control conditions of a pulping process.

The kraft process presents low selectivity at the beginning and end of cooking because of high polysaccharide dissolution [18]. On the other hand, very good selectivity is observed in the pulp yield range of $75-50 \%$. Autocatalysed, organosolv pulping processes tend to be more selective than conventional processes [1], but external addition of acid leads to extended polysaccharide degradation, and consequently, low selectivity [19]. An interesting way of improving the extraction selectivity is by coupling an organic solvent and supercritical carbon dioxide [20,21].

Delignification processes have been reported by several authors to occur in three consecutive phases with different kinetic rates, called initial, bulk and residual phases, for which rate-constants are decreasing in the order mentioned. An excellent review and compilation of kinetics parameters data is given in the handbook by Sixta et al. [22]. The most common approach for the kinetics of isothermal delignification is to consider it occurring as a pseudo, first order process:

$$
L n(L)=k . t
$$

$L$ being the residual lignin on wood and $k$ the rate constant. 
A most accurate treatment involves a non-linear fitting of a sum of three exponentials related to each delignification phase taking place in parallel [22-24]:

$\frac{L(t)}{L_{0}}=A_{i} \cdot e^{-k_{i} t}+A_{b} \cdot e^{-k_{b} t}+A_{r} \cdot e^{-k_{r} t}$

where $L(t)=$ residual lignin on delignified wood,

$L_{0}=$ initial lignin content in wood,

$A_{x}=$ weight fraction related to phase $x$, and

$k_{x}=$ rate constant of the phase $x$.

Several authors have studied the kinetics of polysaccharide extraction during different pulping processes. In acidic media, the most common kinetic model involves two pseudo, first-order steps, one being much faster than the other [19, 26, 27]:

$\frac{P(t)}{P_{0}}=A_{f} \cdot e^{-k_{f} t}+A_{s} \cdot e^{-k_{s} t}+R$

where $P(t)=$ residual polysaccharides on delignified wood,

$P_{0}=$ initial polysaccharide content in wood,

$A_{x}=$ weight fraction related to step $x$, and

$k_{x}=$ rate constant of the step $x$.

$\mathrm{R}=$ Weight fraction of polysaccharides resistant to solubilization).

The faster step is related to hemicelluloses hydrolysis, particularly to xylanes. Two different explanations for the slower step are found in literature. Conner and Lorenz have attributed the existence of this step to the breakdown of lignin-carbohydrate complexes [26] while Aravamuthan et al. have related it to the hydrolysis of amorphous cellulose [27].

Another important effect taking place during the pulping is the topochemistry of delignification. At the beginning of kraft cooking, the lignin extracted comes almost exclusively from the secondary wall. Removal of the lignin present in the middle lamellae only becomes important when about $40 \%$ of the secondary wall lignin has been extracted [28]. In contrast, Pazner and Behera have shown that the extraction of lignin during an organosolv (methanol-water mixture) process occurs from secondary wall and middle lamellae, from the beginning of the process at approximately the same rate [29]. Acetone-water is a very good solvent for lignins, as shown by da Silva Perez et al. [11], Balogh et al. [30], Jimenez et al. [31], Araque et al. [32]. Therefore, great selectivity is expected to occur even from the beginning of the extraction process.

In this work, the kinetics of delignification and polysaccharide extractions, and the selectivity analysis for the organosolv, acetone-water cooking of a hybrid of Eucalyptus urophylla and Eucalyptus grandis, also called Eucalyptus urograndis, are reported. The kinetic parameters for delignification were obtained from both the procedures described by equations (1) and (2), while the polysaccharide extraction parameters were obtained by equation (3). Finally, the process selectivity, calculated as the ratio of extracted lignin over extracted polysaccharides, was studied as an indication for the separation of the different wood fractions in the frame of the biorefinery concept.

\section{EXPERIMENTAL}

Eucalyptus urograndis sawdust (20-60 mesh) was cooked in $120 \mathrm{~mL}$ stainless steel reactors heated by an oil bath, with 10:1 liquor - dry wood ratio at 145, 155, 165, 175, 185 and $195^{\circ} \mathrm{C}$. Acetone-water mixture $(1: 1, \mathrm{v} / \mathrm{v})$ was employed as cooking liquor, based on the conclusions of a previous study about the effect of the liquor composition on the selectivity of the process [11]. Once cooked for the given time, the reactor was immersed in a cold water bath to stop the pulping. The reactor was opened and the spent liquor was immediately separated from the pulp by filtering in order to avoid lignin reprecipitation. The pulp was then washed with an acetone-water solution $(1: 1 \mathrm{v} / \mathrm{v})$ and then with water until neutral pH. Pulp yield and residual lignin content (Klason Lignin - TAPPI T230-om82 method) were determined. Carbohydrate contents were obtained by difference. Correction of the cooking times by $\mathrm{H}$-factor was assumed unnecessary due to the efficient heating system. The chemical composition of the Eucalyptus urograndis wood is presented in Table $\mathbf{1 .}$

Table 1. Composition of Eucalyptus urograndis Wood

\begin{tabular}{|l|c|}
\hline \multicolumn{1}{|c|}{ Component } & $\%$ \\
\hline \hline Extractives (cyclohexane - ethanol) & 2.6 \\
\hline Extractives (water) & 1.4 \\
\hline Klason Lignin & $32.1^{*}$ \\
\hline Holocellulose & $67.5^{*}$ \\
\hline Ash & $0.34^{*}$ \\
\hline
\end{tabular}

*extractive-free basis

\section{RESULTS AND DISCUSSIONS}

\section{Delignification}

The effect of temperature on the pulp yield is presented in Fig. (1). The pulp yield after $120 \mathrm{~min}$. at $195^{\circ} \mathrm{C}$ was about $47 \%$, which is comparable to the traditional chemical delignification processes of hardwood species presenting similar

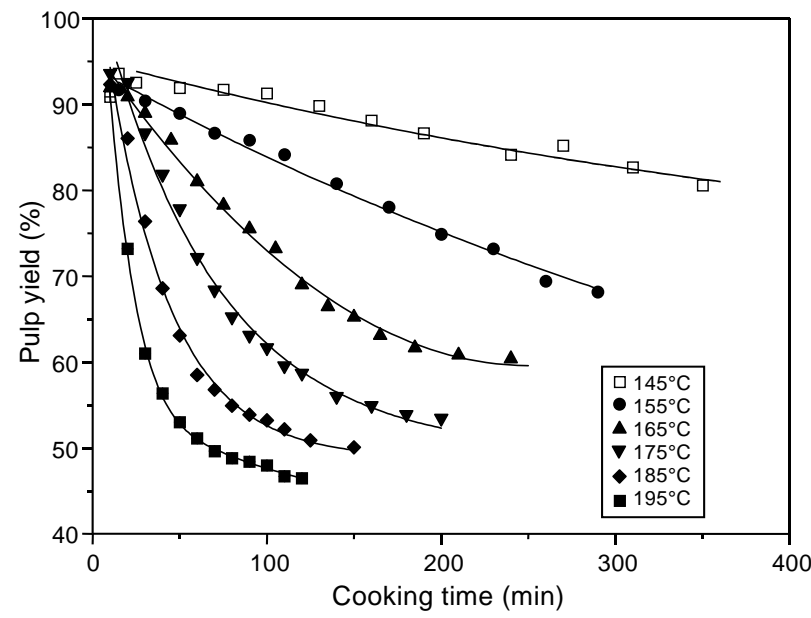

Fig. (1). Temperature-dependence of pulp yield of acetone-water delignification of Eucalyptus urograndis. Temperature icons: $145^{\circ} \mathrm{C}(\square) ; \quad 155^{\circ} \mathrm{C}(\mathbf{\bullet}) ; \quad 165^{\circ} \mathrm{C}(\boldsymbol{\Delta}) ; \quad 175^{\circ} \mathrm{C}(\boldsymbol{\nabla}) ; \quad 185^{\circ} \mathrm{C}(\bullet) ;$ $195^{\circ} \mathrm{C}(\mathbf{\square})$. 
lignin content. Since the pulping process involves both delignification and polysaccharide hydrolysis reactions, which are considerably different, we decided not to perform the kinetics studies (rate constants and activation energy) for the whole pulping process.

Lignin removal percentages are referred here to the initial lignin content. Delignification between 12.1 and $94.6 \%$ was observed under our experimental conditions. The delignification at $145^{\circ} \mathrm{C}$ does not exceed $40 \%$ even after $6.5 \mathrm{~h}$ of cooking, whereas at $195^{\circ} \mathrm{C}, 80 \%$ of the lignin is removed after $1 \mathrm{~h}$ and only about $5 \%$ of lignin remains in the pulp after $2 \mathrm{~h}$.

The pseudo, first order kinetics behaviour of delignification process (eq. 1) is shown in Fig. (2a) and the values of rate constants obtained from the slope of the straight lines are presented in Table $\mathbf{2}$. We can identify the existence of bulk phase for all the temperatures studied while the residual phase is observed for temperatures above $165^{\circ} \mathrm{C}$. The transition between bulk and residual phases is strongly affected by the cooking temperature. Two concurrent phenomena probably contribute to this behaviour: i) at higher temperatures the breakdown of lignin and lignin-carbohydrates complexes takes places easily; ii) the polysaccharides extraction rate is also heavily affected by the temperature takes leading to the creation of higher pores in the cell wall structure according to the 'sieve effect' theory.

The fitting of equation 2 by non-linear regression was also performed and the curves obtained are shown in Fig. (2b). The rate constants obtained from the previous treatment were used as input parameters for the iterative calculation process. Since the initial delignification phase was not identified by the linear treatment, hypothetical values were adopted for the rate constants in order to start the iterative calculation. By using this mathematical treatment, besides the bulk and the residual phases previously identified, the initial delignification phase for temperatures between 145 and $165^{\circ} \mathrm{C}$, was also observed. The rate constants and the extracted lignin fractions obtained from the non-linear fitting of equation (2) are presented in Table 3. Excepting for the residual phase, the rate constant values were found to be slightly higher than those found by the linear fitting model.

We observe that most lignin ( 80 to $90 \%$ ) is extracted during the bulk phase. During both initial and residual delignification phases the percentage of lignin extraction is no higher than $15 \%$. The lignin extraction is therefore quite

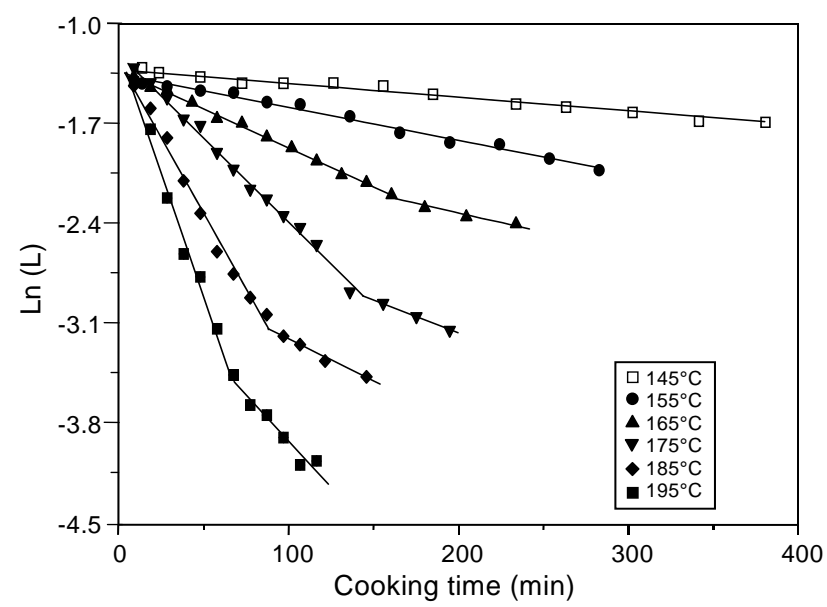

(a)

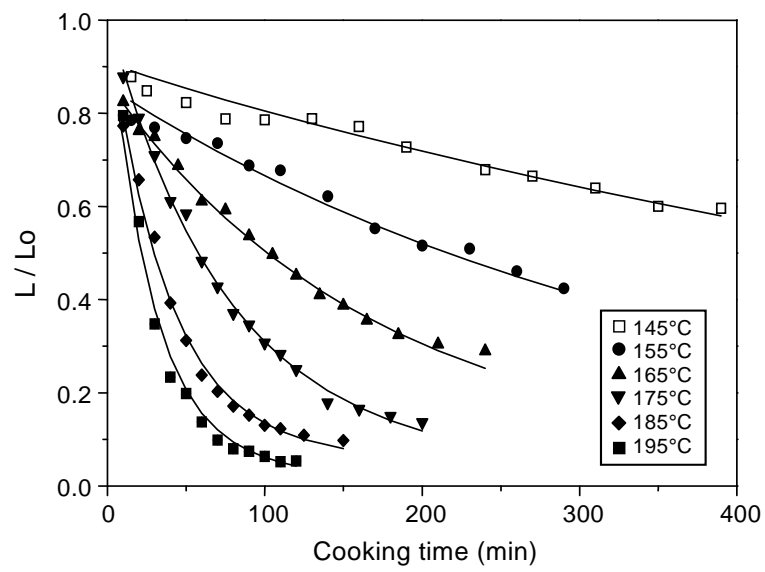

(b)

Fig. (2). Linear (a) and non-linear (b) first order kinetics behaviour of acetone-water delignification of Eucalyptus urograndis. Temperature icons: $145^{\circ} \mathrm{C}(\square) ; 155^{\circ} \mathrm{C}(\bullet) ; 165^{\circ} \mathrm{C}(\boldsymbol{\Delta}) ; 175^{\circ} \mathrm{C}(\boldsymbol{\nabla})$; $185^{\circ} \mathrm{C}(\diamond) ; 195^{\circ} \mathrm{C}(\boldsymbol{\square})$.

different from kraft cooking. Sixta et al. [22] collected literature data on the lignin extracted in each one of the three phases for different wood species. The values show that, for kraft cooking, the bulk phase represents 64 to $78 \%$ of the extracted lignin. Although important amount of lignin is extracted during initial phase of kraft cooking (18 to $31 \%$ ), this fraction is a mixture of lignin and degraded polysaccharides. Indeed, large amount of polysaccharides-like materials

Table 2. Rate Constants and Delignification Ranges for the Pseudo, First Order Kinetics Model (eq. 1) of Acetone-Water Pulping of Eucalyptus urograndis Wood

\begin{tabular}{|c|c|c|c|}
\hline Temperature & \multicolumn{2}{|c|}{ Rate Constants } & Bulk-Residual Phases Transition \\
\hline$\left({ }^{\circ} \mathbf{C}\right)$ & $\mathbf{k}_{\mathbf{b}} \mathbf{x} \mathbf{1 0}^{\mathbf{3}}\left(\mathbf{m i n}^{-\mathbf{1}}\right)$ & $\mathbf{k}_{\mathbf{r}} \mathbf{x} \mathbf{1 0}^{\mathbf{3}}\left(\mathbf{m i n}^{-1}\right)$ & \\
\hline 145 & 0.97 & & \\
\hline 155 & 2.30 & & \\
\hline 165 & 5.41 & 2.68 & 64.4 \\
\hline 175 & 11.7 & 4.56 & 78.8 \\
\hline 185 & 21.7 & 6.90 & 85.8 \\
\hline 195 & 34.5 & 12.8 & 86.3 \\
\hline
\end{tabular}


Table 3. Rate Constants and Weight Fractions for the Sum of Exponential Kinetics Model (eq.2) of Acetone-Water Pulping of Eucalyptus urograndis Wood

\begin{tabular}{|c|c|c|c|c|c|c|c|}
\hline $\mathbf{T}\left({ }^{\circ} \mathbf{C}\right)$ & $k_{i} \cdot 10^{3}\left(\min ^{-1}\right)$ & $\mathrm{A}_{\mathrm{i} \cdot \mathbf{1 0}}{ }^{2}$ & $k_{b} \cdot 10^{3}\left(\min ^{-1}\right)$ & $\mathrm{A}_{\mathrm{b}} \cdot \mathbf{1 0 ^ { 2 }}$ & $\mathbf{k}_{\mathrm{f} \cdot 10^{3}\left(\mathrm{~min}^{-1}\right)}$ & $\mathbf{A}_{\mathrm{f} .} \mathbf{1 0}^{2}$ & $\mathbf{R}$ \\
\hline 155 & 5.39 & 0.073 & 2.35 & 0.774 & & & 0.153 \\
\hline 165 & 10.8 & 0.070 & 5.69 & 0.796 & 2.45 & 0.071 & 0.063 \\
\hline 175 & & & 14.6 & 0.891 & 4.81 & 0.071 & 0.038 \\
\hline 195 & & & 40.1 & 0.900 & 12.7 & 0.095 & 0.005 \\
\hline
\end{tabular}

is also extracted during this phase. As the separation of the wood components dissolved in the black liquor is one of the major difficulties for the biorefinery approach in kraft pulp mills, a more selective process during initial phase would allow better utilisation and value-adding to these extracted fractions.

Arrhenius' activation energies were determined for the different phases identified through both linear and non-linear approaches. Fig. (3) shows the variation of rate constants, natural logarithm as a function of the reciprocal cooking temperature. The activation energy calculated from the slope of the straight lines is presented in Table 4. Insignificant differences between the activation energies for the two kinetic treatments were observed, despite the slight differences between the rate constants.

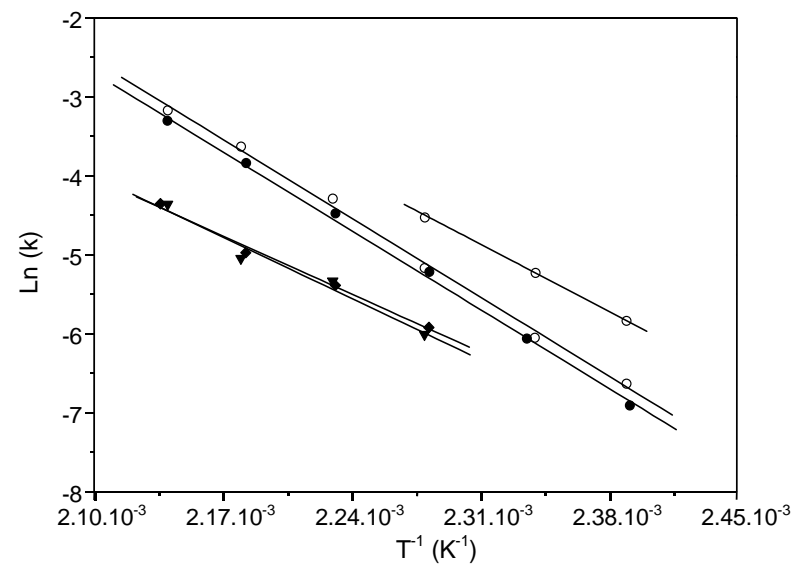

Fig. (3). Arrhenius plot for the different delignification phases (initial - top; bulk - middle; residual - bottom) of acetone-water delignification of Eucalyptus urograndis, studied by non-linear $(\boldsymbol{\Delta}$, $\boldsymbol{\bullet}, \boldsymbol{\nabla})$ and linear $(\boldsymbol{\square}, \bullet)$ models.

The activation energy values obtained here correspond to the values reported in literature for both traditional and organosolv, hardwood delignification processes. Sixta et al. [22] have compiled activation energy data for the bulk phase from different authors about the kraft cooking of hardwoods varying from 115 to $132 \mathrm{~kJ} \cdot \mathrm{mol}^{-1}$. Curvelo et al. [8] and Pereira et al. [33] have respectively reported activation energies of 108.4 and $107.9 \mathrm{~kJ} \mathrm{~mol}^{-1}$ for the bulk phase of ethanol-water delignification of Eucalyptus globulus wood.

Since the delignification process mainly occurs through the breakdown of $\alpha-0-4$ and $\beta-0-4$ ether bonds, we can relate the activation energies obtained here for the delignification to the values published for the acidic hydrolysis of the lignin model containing these chemical bonds. Meshigini and Sarkanen [34] have reported activation energies from 79 to 102 $\mathrm{kJ} \mathrm{mol}^{-1}$ for the acidic hydrolysis $\alpha-0-4$, depending on the substituents, while Sarkanen and Hoo [35] have found values around $150 \mathrm{~kJ} . \mathrm{mol}^{-1}$ for $\beta-0-4$ lignin model compounds. Based on these values, it is reasonable to suppose that part of $\alpha-\mathrm{O}-4$ linkages is hydrolysed during initial delignification and that the remaining $\alpha-0-4$ and $\beta-0-4$ ether linkages are cleaved in the bulk phase.

The activation energy values obtained for the residual phase remain incomprehensible when related to model lignin hydrolysis because the extension of delignification occurring during this phase is not too small for kinetics analysis.

\section{Extraction of Polysaccharides}

The kinetics behaviour of polysaccharide extraction is presented in Fig. (4) and the values of rate constants, obtained by non-linear regression (eq. 3), are presented in Table $\mathbf{5}$. We can identify the existence of the faster rate step for all the temperatures studied while the slower one is only observed for temperatures inferior to $175^{\circ} \mathrm{C}$. However, it is clear from Fig. (5), which presents the Arrhenius plot for both kinetic phases, that for temperatures higher than $185^{\circ} \mathrm{C}$, both reactions occur at the same rate. The selectivity of polysaccharides extraction is therefore strongly dependent on the cooking temperature. The lower the cooking temperature, the higher the possibility of differentiating the polysaccharides extracted during the fast and the slow kinetics phases.

Table 4. Arrhenius' Activation Energy for the Acetone-Water Delignification Processes of Eucalyptus urograndis Wood

\begin{tabular}{|l|c|c|c|}
\hline \multicolumn{1}{|c|}{ Kinetics approach } & Initial phase (kJ.mol $\left.{ }^{\mathbf{1}}\right)$ & Bulk phase (kJ.mol $\left.^{\mathbf{1}}\right)$ & Residual phase $\left(\mathbf{k J . m o l}^{\mathbf{1}}\right)$ \\
\hline \hline Linear model (eq. 1) & & $118.3 \pm 4.7$ & $87.1 \pm 5.3$ \\
\hline Non-linear model (eq. 2) & $102.3 \pm 3.7$ & $117.7 \pm 6.1$ & $89.0 \pm 9.6$ \\
\hline
\end{tabular}




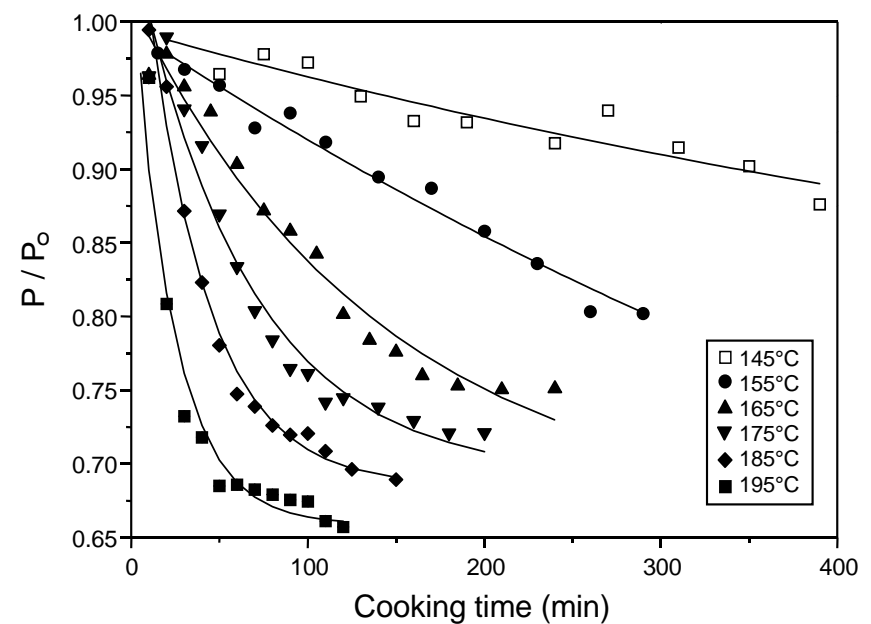

Fig. (4). Non-linear kinetics behaviour of polysaccharide removal during acetone-water pulping of Eucalyptus urograndis. Temperature icons: $145^{\circ} \mathrm{C}(\square) ; 155^{\circ} \mathrm{C}(\boldsymbol{O}) ; 165^{\circ} \mathrm{C}(\boldsymbol{\Delta}) ; 175^{\circ} \mathrm{C}(\boldsymbol{\nabla}) ; 185^{\circ} \mathrm{C}$ $(\diamond) ; 195^{\circ} \mathrm{C}(\mathbf{\square})$.

Arrhenius' activation energies, calculated from slope of the straight lines shown in Fig. (5), are $119.4 \pm 7.6$ and 176.9

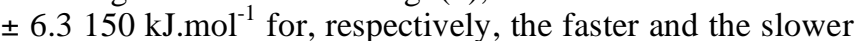
hydrolysis rates. Polysaccharide removal seems to be much more sensitive to the solvent media than delignification process, especially the rapid hydrolysis. This can be confirmed when the activation energy values obtained here are compared to certain results reported in literature. The activation energy published for the faster hydrolysis kinetics of the acetic acid-water pulping, is in the range $84-88 \mathrm{~kJ}^{-\mathrm{mol}^{-1}}[19$, 25-27]. However, when small amounts of hydrochloric acid are added, the activation energy dramatically drops. For example, when the $\mathrm{HCl}$ concentration in the acetic acidwater liquor is $0.014 \mathrm{M}$ or $0.027 \mathrm{M}$, the activation energies are 39.5 and $44.6 \mathrm{~kJ} \mathrm{~mol}^{-1}$, respectively. On the other hand, the activation energy for slower hydrolysis kinetics remains unchanged (around $124 \mathrm{~kJ}^{\mathrm{mol}}{ }^{-1}$ ). By comparing the values obtained during this work (Table 6) and those mentioned above, it seems that the presence of acetone in the liquor protects the polysaccharides from degrading, since the activation energies are considerably higher. This observation clearly confirms earlier results obtained on the effect of the acetone-water liquor composition on pulping performance, delignification and polysaccharide removal [11]. Eucalyptus urograndis wood was cooked at $185^{\circ} \mathrm{C}$ for 2 hours in acetone-water liquors containing acetone from 0 to $100 \%$ in volume. We observed that the amount of polysaccharides extracted during the cooking trials with liquor, varying from 0 to $30 \%$ in acetone, is almost equal at about $30 \%$. However, if the liquor composition used in this work is $50 \%$ acetone, the selectivity is increased and the polysaccharide removal is reduced to $21 \%$.

\section{Selectivity}

By plotting both lignin and polysaccharide removal as a function of the pulp yield, a temperature-independent analysis of the process becomes possible, as showed in Fig. (6). The format of the curves suggests there is an interesting correlation between delignification and polysaccharide extraction during the process. Polynomial fitting of the data was used to generate the lines shown in Fig. (6).

In order to evaluate the selectivity during pulping, the ratio of extracted wood component (lignin over polysaccharides) was adopted. Fig. (7) shows the accumulated selectivity of the process as function of pulp yield. The selectivity parameter was found to be very high at the beginning of the processes but quickly descends during the range of $95-85 \%$ yield, tending to a levelling-off value at around 1.5.

Although accumulated selectivity is important to the control of both pulping conditions and pulp properties, Fig. (7) does not give any idea of the actual selectivity at a given moment of the pulping. This can be found from the first derivative of the fitted curves included in Fig. (6), according to Masura's procedure [18]. However, as the curves were obtained by data fitting and not by modelling, only a qualitative analysis of the actual lignin and polysaccharide extraction was performed (Fig. 8). The delignification rate is very high from the beginning of the process until $85 \%$ yield, it decreases to a minimum at $76 \%$ yield, and increases to a maximum centered at $58 \%$ yield. The polysaccharide extraction rate is very low in the beginning, passes throughout a maximum at around $74 \%$ and then decreases to a minimum at $56 \%$ pulp yield. At the end of the pulping, delignification becomes very difficult and the high values of polysaccharide degradation tend to suggest cellulose degradation. The format of the lignin and polysaccharide extraction distribution curves confirms the important degree of correlation existing between the two processes. When the extraction of one component reaches a maximum, the other is at a minimum and vice-versa. The two maxima of the delignification selectivity are present along the cooking process: one from the begin-

Table 5. Rate Constants and Weight Fractions for the Sum of Two Exponential Kinetics Models (eq. 3) for Polysaccharide Extraction During the Acetone-Water Pulping of Eucalyptus urograndis Wood

\begin{tabular}{|c|c|c|c|c|c|}
\hline Temperature $\left({ }^{\circ} \mathrm{C}\right)$ & $\mathbf{k}_{f} \cdot 10^{3}\left(\mathrm{~min}^{-1}\right)$ & $\mathbf{A}_{f}$ & $k_{s} \cdot 10^{3}\left(\mathrm{~min}^{-1}\right)$ & $\mathbf{A}_{s}$ & $\mathbf{R}$ \\
\hline 145 & 1.31 & 0.252 & 0.244 & 0.042 & 0.705 \\
\hline 165 & 7.54 & 0.306 & 2.65 & 0.065 & 0.628 \\
\hline 175 & 16.5 & 0.315 & 7.63 & 0.082 & 0.602 \\
\hline 195 & 42.5 & 0.421 & & & 0.579 \\
\hline
\end{tabular}




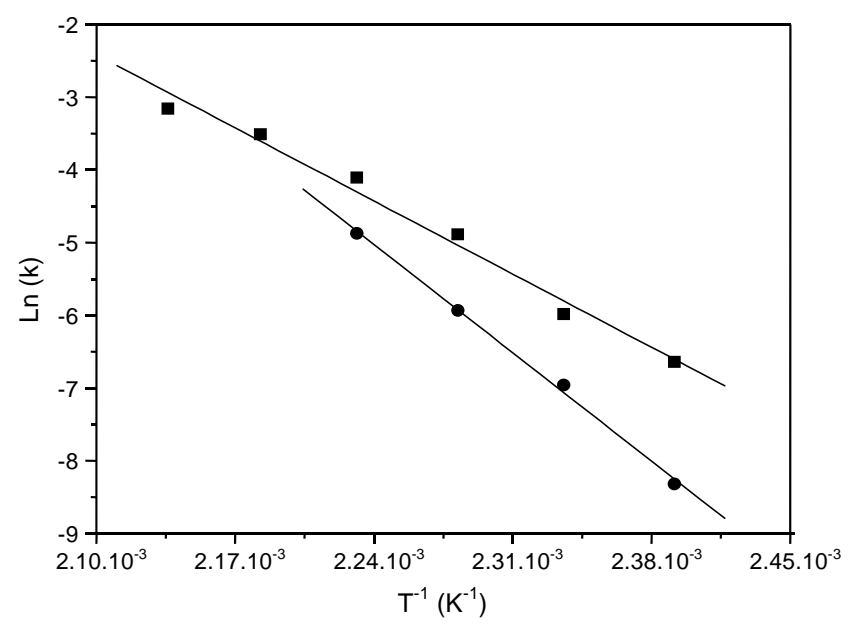

Fig. (5). Arrhenius plot for the rapid (ם) and slow (0) rate hydrolysis of polysaccharides during the acetone-water pulping of Eucalyptus urograndis.

Table 6. Arrhenius' Activation Energy for the Polysaccharides Removal Using Acetone-Water Pulping of Eucalyptus urograndis Wood

\begin{tabular}{|c|c|c|}
\hline Kinetics Approach & $\begin{array}{c}\text { Fast Hydrolysis } \\
\text { (kJ.mol }^{-1} \text { ) }\end{array}$ & $\begin{array}{c}\text { Slow Hydrolysis } \\
\text { (kJ.mol }^{\mathbf{1}} \text { ) }\end{array}$ \\
\hline \hline $\begin{array}{c}\text { Non-linear model } \\
\text { (eq. 3) }\end{array}$ & $119.4 \pm 7.6$ & $176.9 \pm 6.3$ \\
\hline
\end{tabular}

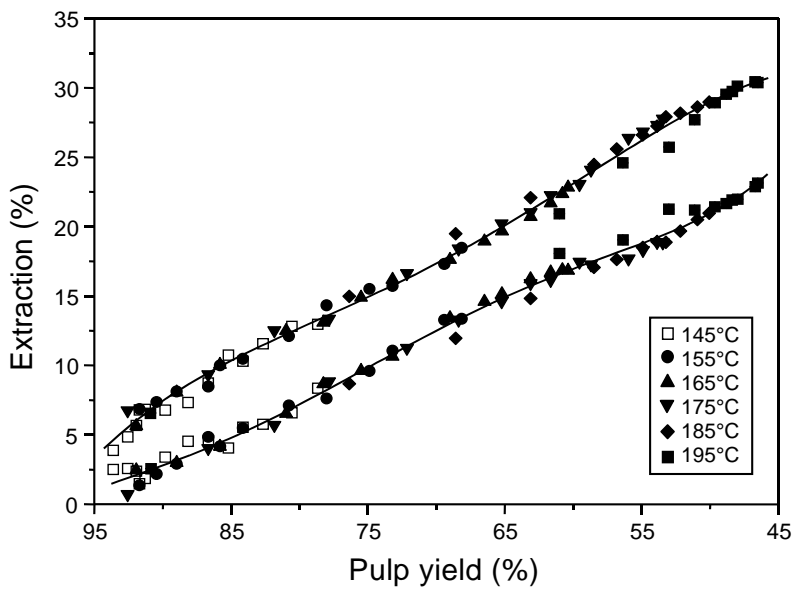

Fig. (6). Temperature-independent profile of lignin (top) and polysaccharide (bottom) extraction during acetone-water pulping of Eucalyptus urograndis. Temperature icons: $145^{\circ} \mathrm{C}(\square) ; 155^{\circ} \mathrm{C}(\bigcirc)$; $165^{\circ} \mathrm{C}(\boldsymbol{\Delta}) ; 175^{\circ} \mathrm{C}(\boldsymbol{\nabla}) ; 185^{\circ} \mathrm{C}(\diamond) ; 195^{\circ} \mathrm{C}(\boldsymbol{\square})$.

ning of the process to $75 \%$ pulp yield and the second one is centred at $58 \%$. As expected from the lignin and polysaccharide extraction behaviours, selectivity at the end of the process is very low.

The behaviour of wood component removal during acetone-water, organosolv pulping is quite different from that observed for alkaline (kraft and soda) delignification as reported by Masura [36,37]. The author showed that serious polysaccharides removal occurs in the beginning of the pro-

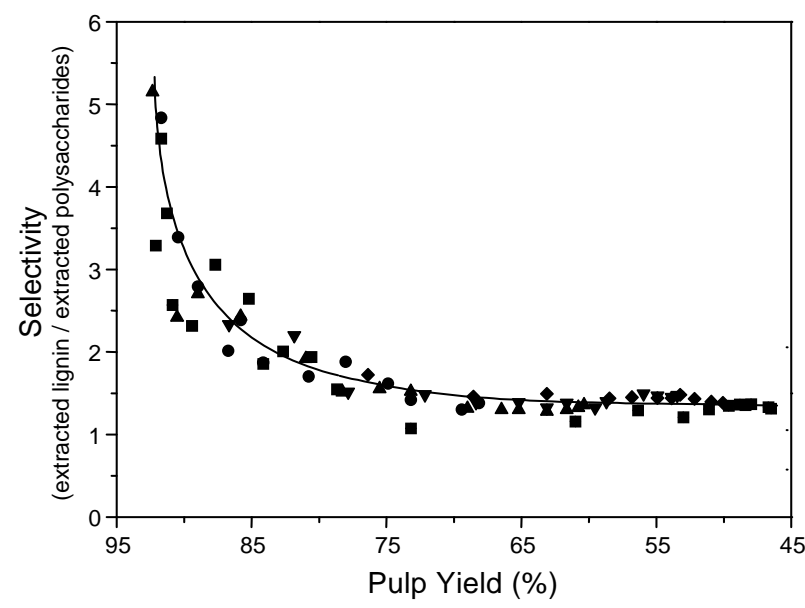

Fig. (7). Accumulated selectivity of acetone-water pulping of Eucalyptus urograndis.

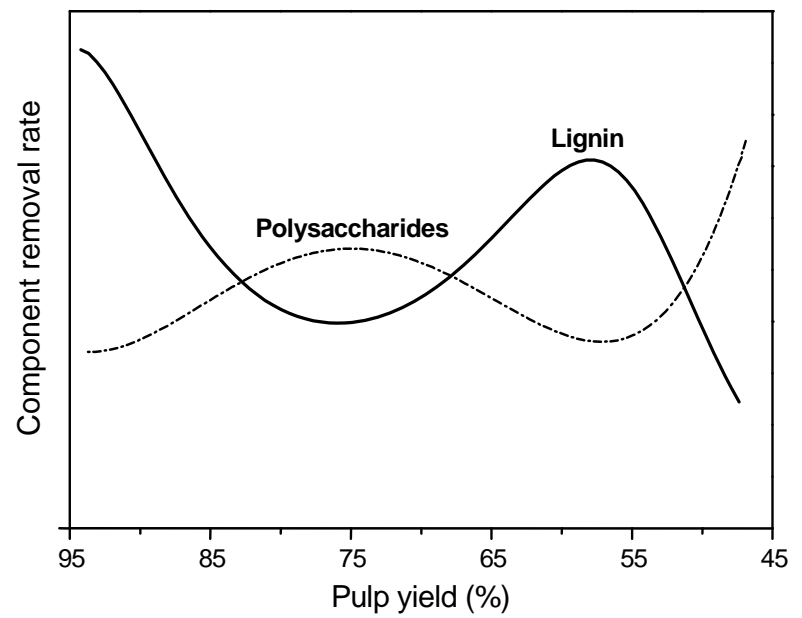

Fig. (8). Distribution of lignin (- $(-)$ and polysaccharides (-・-・-) extraction as function of pulp yield during the acetone-water cooking of Eucalyptus urograndis. These curves were obtained as the first derivative of the fitted curves presented in Fig. (6).

cess (100 - 85\% of pulp yield) when the extraction of lignin is almost negligible. However, in the range of $85-50 \%$ pulp yield, the rate of lignin removal rapidly increases while the polysaccharide extraction rate becomes very low. Lignin selectivity is consequently very low in the range of 100 $85 \%$ yield, followed by a maximum at around approximately $60 \%$ and decreases until the end of cooking. The accumulated selectivity is totally different in the two processes. For organosolv pulping, the format of the curve is an exponential decay (Fig. 6), while for the kraft process, a bell-shape curve is observed: the selectivity being very low until $85 \%$ pulp yield, suddenly rising to a maximum around $65-70 \%$, and then decreasing again to very low values at around $50 \%$.

Some factors can be invoked here to explain the differences observed between the processes. The first one is the so-called 'sieve effect' theory of delignification proposed by Göring and co-workers $[17,37,38]$. According to the authors, there is a correlation between the molecular weight of extracted lignin fragments and the size of the pores in cell walls 
during the delignification process. Thus, in the beginning of the kraft pulping process, polysaccharides removed from the cell walls enlarge the pores permitting extraction of the lignin fragments. Moreover, it is known that the strongly alkaline kraft liquor easily dissolves part of the hemicelluloses. In neutral (beginning of the acetone-water, organosolv process) and slightly acidic (after part of acetate groups present in the wood have been hydrolysed) media, the dissolution of hemicelluloses is less effective. During organosolv delignification, the better solubility of lignin fragments in the organic solvents, compared to the alkaline liquor, especially at the beginning of the process, might be a major difference. This could explain the high selectivity observed here at the beginning of the process. After this initial behaviour, the removal of polysaccharides is required to let the lignin fragments be extracted as illustrated by the low selectivity between the 80 and $70 \%$ yield, followed by the maximum at $58 \%$ yield.

The kinetics and selectivity information described here demonstrate the potential of organosolv acetone-water pulping in the frame of a biorefinery approach. Lignin-like fragments can be selectively extracted in the beginning of the pulping process and these fractions can be easily separated from the spent black liquor, purified and used as started material for different applications. Then, during the bulk phase, polysaccharides are mainly extracted and this fraction, after the solvent separation, can be used for the production of biofuel via saccharification and fermentation. The last fractions obtained during the residual phase of delignification being constituted of a mixture of lignin and polysaccharides, including lignin-carbohydrates complexes, would be very difficult to purify and could be preferentially be used to provide energy for the solvent evaporation.

\section{CONCLUSIONS}

Organosolv, acetone-water pulping of Eucalyptus urograndis (a hybrid of Eucalyptus urophylla and Eucalyptus grandis) wood was carried out at temperatures ranging from $145^{\circ} \mathrm{C}$ to $195^{\circ} \mathrm{C}$. Studies were performed on kinetics of lignin and polysaccharide removal, and on selectivity.

The pseudo, first-order kinetics of delignification were analysed through two mathematical approaches. First, the rate constants were estimated from linear fitting of natural logarithms as a function of cooking time. Then, the rate constants obtained from the linear fitting were used as initial values in a non-linear fitting using a sum of three exponential terms related to initial (phase I), bulk (phase II) and residual (phase III) delignification. According to this latter procedure, the phase I occurs when cooking is carried out at $145^{\circ} \mathrm{C}, 155^{\circ} \mathrm{C}$, and $165^{\circ} \mathrm{C}$, while phase II was observed for all the temperatures studied. Phase III was identified only for temperatures above $165^{\circ} \mathrm{C}$.

Arrhenius' activation energies of initial, bulk and residual delignification phases, were estimated respectively at $102.3,117.7$ and $89.0 \mathrm{~kJ}^{-\mathrm{mol}^{-1}}$ from the rate constants obtained by the non-linear fitting approch. These values can be related to the cleavage of $\alpha-\mathrm{O}-4$ linkages during the initial phase, and to the remaining $\alpha-\mathrm{O}-4$ and the $\beta-\mathrm{O}-4$ linkages during in the bulk phase.

Kinetics of polysaccharide removal were studied by using a sum of two exponential equations related to the hy- drolysis of wood carbohydrates occurring at two different rates. The faster reaction was observed at all the temperatures studied while the slower is observed for temperatures below $175^{\circ} \mathrm{C}$. However, for temperatures above $185^{\circ} \mathrm{C}$, both reactions occur with the same rate. Activation energies of 119.4 and $177.9 \mathrm{~kJ}$ for slower and faster reactions, respectively, were obtained.

The ratio of extracted lignin over extracted polysaccharide was adopted as a selectivity parameter. We observed that, in contrast to kraft pulping, high selectivity is observed in the beginning of acetone-water pulping and decreases along the pulping process. The overall selectivity at the end of the process was 1.5 . In order to get the actual selectivity at a given moment of the cooking process, the first derivative of the delignification and polysaccharide removal curves was obtained. The format of the distribution curves reveals two regions of high selectivity: the first one from the beginning of the process until $85 \%$ pulp yield, and the second at $65 \%$ to $54 \%$ pulp yield. Three different fractions of extracted material can be obtained using this process: the first one rich in lignin at the beginning of the process can be used for the production of high added-value lignin based products, the second one rich in polysaccharides can be proposed for the production of biofuel, and finally the third one for providing energy for the pulping process.

\section{ACKNOWLEDGEMENT}

The authors acknowledge CNPq for financial support.

\section{REFERENCES}

[1] Johansson A, Aaltonen O, Ylinen P. Organosolv pulping - methods and pulp properties. Biomass 1987; 13(1): 45-65.

[2] Aziz S, Sarkanen KV. Organosolv pulping - a review. TAPPI J 1989; 72(3): 169-75.

[3] Aziz S, McDonough TJ. Solvent pulping - promise and programs. TAPPI J 1988; 71(2): 251-6.

[4] Paszner L, Cho HJ. Organosolv pulping: acid catalysis options and their effect on fiber quality and delignification. TAPPI J 1989; 72(2): 135-142.

[5] Sarkanen KV. Chemistry of solvent pulping. TAPPI J 1990; 73(10): 215-9.

[6] McDonough TJ. The chemistry of organosolv delignification. TAPPI J 1993; 76(8): 186-93.

[7] Hergert, HL. Developments in Organosolv Pulping - an Overview. In: Young RA, Akhtar M, Eds. Environmentally Friendly Technologies for the Pulp and Paper Industry New York: John Wiley \& Sons, 1998; pp. 5-67.

[8] Curvelo AAS, Pereira R. Kinetics of ethanol-water delignification of sugar cane bagasse. Paper presented at the $8^{\text {th }}$ International Symposium on Wood and Pulping Chemistry, Helsinki, June 6-9, 1995.

[9] Curvelo AAS, Araujo ES, Sansigolo CA. Kinetics of organosolv pulping of Eucalyptus globulus. Paper presented at the $8^{\text {th }}$ International Symposium on Wood and Pulping Chemistry, Helsinki, June 6-9, 1995.

[10] Sansígolo CA. Curvelo AAS.995. Cinética de polpação em etanolágua e propriedades da polpa de Eucalyptus globulus. Papel 1995; 8: $39-45$.

[11] da Silva Perez D, Araujo ES, Curvelo AAS. Polpação acetona-água dos Eucalyptus globulus e urograndis: 1. Efeito da composição da mistura solvente. Papel 1997; 7: 73-82.

[12] Yawalata D, Pazner L. Cationic effect in high concentration alcohol organosolv pulping: the next generation biorefinery. Holzforschung 2004; 58 (1): 7-13.

[13] Pan X, Arato C, Gilkes N, et al. Biorefining of softwoods using ethanol organosolv pulping: Preliminary evaluation of process streams for manufacture of fuel-grade ethanol and co-products, Biotechnol Bioeng 2005; 90(4): 476-81. 
[14] Pan X, Xie D, Kang KY, Yoon SL, Saddler JN. Effect of organosolv ethanol pretreatment variables on physical characteristics of hybrid poplar substrates. Appl Biochem Biotech 2007; 136-140 (1-12): 367-77.

[15] Arato C, Pye EK, Gjennestad G. The Lignol approach to biorefining of woody biomass to produce ethanol and chemicals. Appl Biochem Biotech 2005; 123 (1-3): 871-82.

[16] Pye EK. Industrial Lignin Production and Applications. Biorefineries-Industrial Processes and Products In: Kamm B, Gruber PR, Kamm M, Eds. New York: Wiley-VCH Verlag GmbH \& Co 2008; 165-200.

[17] Göring DAI. Polymer properties of lignin and lignin derivatives. Lignin - occurrence, formation, structure and reactions In: Sarkanen KV Ludwig CH, Eds. New York: John Wiley \& Sons 1971; 695-768.

[18] Masura V. Mathematical model for kraft and soda pulping of scandinavian spruce. Cell Chem Technol 1993; 27(5): 537-54.

[19] Vazquez G, Antorrena G, Gonzalez J. Kinetics of polysaccharide hydrolysis in the acid-catalysed delignification of Eucaluptus globulus wood by acetic acid. J Wood Sci Technol 1995; 30(1): 318.

[20] Pasquini D, Pimenta, MTB, Ferreira LH, Curvelo AAS. Sugar cane bagasse pulping using supercritical $\mathrm{CO} 2$ associated with co-solvent 1-butanol/water. J Supercrit Fluid 2005; 34(2): 125-31.

[21] Pasquini D, Pimenta MTB, Ferreira LH, Curvelo AAS. Extraction of lignin from sugar cane bagasse and Pinus taeda wood chips using ethanol-water mixtures and carbon dioxide at high pressures. $\mathbf{J}$ Supercrit Fluid 2005; 36(1): 31-9.

[22] Sixta H, Potthast A, Krotschek AW. Chemical Pulping Processes In: Sixta H, Ed. Handbook of Pulp, Weinheim: Wiley-VCH Verlag 2006; 185-229.

[23] Chiang VL, Yu J, Eckert RC. Isotermal reaction kinetics of kraft delignification of douglas-fir. J Wood Chem Technol 1990; 10(3): 293-310.

[24] Labidi A, Pla F. Délignification en milieu alcalin de bois feuillus à l'aide d'un réacteur à lit fixe et à faible temps de passage. II. Développements cinétiques. Holzforschung 1992; 46(2): 155-61.

[25] Conner AH, Lorenz LF. Kinetic modeling of hardwood prehydrolysis. Part III. Water and dilute acetic acid prehydrolysis of southern red oak. Wood Fiber Sci 1986; 18(2): 248-63.
[26] Conner AH. Kinetic modeling of hardwood prehydrolysis. Part I. Xylan removal by water prehydrolysis. Wood Fiber Sci 1984; 16(2): 268-77.

[27] Aravamuthan R, Chen W, Zargarian K, April G. Chemicals from wood: prehydrolysis/organosolv methods. Biomass 1989; 20(3-4): 263-76.

[28] Procter AR, Yean WQ, Göring DAI. The topochemistry of delignification in kraft and sulphite pulping of spruce wood. Pulp Pap Mag Can 1967; 68(9): T445-60.

[29] Paszner L, Behera NC. Topochemistry of softwood delignification by alkali earth metal salt catalysed organosolv pulping. Holzforschung 1989; 43(3): 159-68.

[30] Balogh DT, Curvelo AAS, De Groote RAMC. Solvent effect on organosolv lignin from Pinus caribea Hondurensis. Holzforschung 1992; 46(4): 343-48

[31] Jiménez L, de la Torre MJ, Bonilla JL, Ferrer, JL. Organosolv pulping of wheat straw by use of acetone-water mixtures. Process Biochem 1998; 33(4): 401-8.

[32] Araque E, Parra C, Freer J, et al. Evaluation of organosolv pretreatment for the conversion of Pinus radiata D. Don to ethanol. Enzyme Microb Technol 2008; 43(2): 214-9.

[33] Pereira H, Oliveira MF, Miranda I. Kinetics of ethanol-water pulping and pulp properties of Eucalyptus glubulus Lab. Appita 1986; 39(6): 455-8.

[34] Meshigini M, Sarkanen KV. Synthesis and kinetics of acidcatalyzed hydrolysis of some $\alpha$-aryl ether lignin model compound. Holzforschung 1989; 43(4): 239-43.

[35] Sarkanen KV, Hoo LH. Kinetics of hydrolysis of erythroguaiacylglycerol $\beta$-(-2-Methoxyphenyl) ether and its veratryl analogue using $\mathrm{HCl}$ and aluminum chloride as catalysts. J Wood Chem Technol 1991; 1(1): 11-27.

[36] Masura V. Alkaline degradation of spruce and beech wood. Wood Sci Technol 1992; 16(2): 155-64.

[37] Alhgren PA, Yean WQ. Göring DAI. Chlorite delignification of spruce wood - Comparison of molecular weight of the lignin dissolved with the size pores in the cell wall. TAPPI J 1971; 54(5): 737-40.

[38] Göring DAI. The Lignin Paradigm. Lignins - Properties and Materials In: Glasser WG, Sarkanen S, Eds. ACS Symposium Series, Washington 1989; 2-10.

This is an open access article licensed under the terms of the Creative Commons Attribution Non-Commercial License (http://creativecommons.org/licenses/ by-nc/3.0/) which permits unrestricted, non-commercial use, distribution and reproduction in any medium, provided the work is properly cited. 